UDC 1:122:316.422

LBC 87.6

\title{
TECHNOGIZATION OF SOCIETY AS A FACTOR OF SOCIO-CULTURAL MODERNIZATION
}

\author{
Sergei I. Pelevin \\ Armavir State Pedagogical University, Armavir, Russian Federation
}

\begin{abstract}
According to the author, the development processes of modern society are relevantly described using the theories of the information society and the knowledge society. In this regard, the modern directions of research carried out within the framework of the socio-information paradigm are indicated (in particular, the consideration of the influence of digital technologies on social changes and the dynamics of digital inequality in society). Attention is drawn to the fact that in the theories of the information society and the knowledge society, the central issue is the strategies for technologizing social practices and their consequences for society and individuals. It is noted that the technologization of social practices changes the structure and forms of communication processes between social actors and the dynamics of the development and functioning of various elements of the social system. The article shows the mechanism of sociocultural regulation of modernization processes, which in modern society is the technicalization of social practices. Technologization of society can be understood as a process of a gradual structural and functional transition of all social systems from a traditional society to an industrial one, and then to a postindustrial one, as well as the formation and approval of new institutions and modern systemic features in society. The dynamics of socio-cultural modernization is greatly influenced by the global technogenic context, which acts as an exogenous factor in the modernization process. It is argued that technologization, in addition to its own, purely material, technical and economic meanings, also has instrumental significance as an integrated regulator of social processes, and consists of false methods of structural and functional impact on the political, social and spiritual-value spheres of modern society. It is noted that socio-political modernization is in close interdependence with technological modernization. Moreover, a rather complicated interaction takes place between the development tracks of ethnic and national cultures and the process of political modernization.
\end{abstract}

Key words: technologization, modernization, sociocultural modernization, conservative modernization, democracy, authoritarian system.

УДК 1:122:316.422

ББК 87.6

\section{ТЕХНОЛОГИЗАЦИЯ ОБЩЕСТВА КАК ФАКТОР СОЦИОКУЛЬТУРНОЙ МОДЕРНИЗАЦИИ}

\section{Сергей Игоревич Пелевин}

Армавирский государственный педагогический университет, г. Армавир, Российская Федерация

\footnotetext{
Аннотация. По мнению автора, процессы развития современного общества релевантно описываются с помощью теорий информационного общества и общества знаний. В связи с этим указаны современные ح направления исследований, проводимые в рамках социально-информационной парадигмы (в частности, 궁 рассмотрение влияния цифровых технологий на социальные изменения и динамики цифрового неравенства в обществе). Обращено внимание на то, что в теориях информационного общества и общества знаний 己 центральным является вопрос о стратегиях технологизации социальных практик и их последствий для социума и индивидов. Отмечено, что технологизация социальных практик изменяет структуру и формы процессов коммуникации между социальными субъектами и динамику развития и функционирования различных элементов общественной системы. В статье показан механизм социокультурной регуляции процессов модер() низации, в качестве которого в современном обществе выступает технизация социальных практик. Техноло-
} 
гизация общества может быть понята как процесс поэтапного структурного и функционального перехода всех общественных систем от традиционного общества к индустриальному и затем - к постиндустриальному, а также как формирование и утверждение в обществе новых институтов и современных системных особенностей. На динамику социокультурной модернизации большое влияние оказывает мировой техногенный контекст, выступающий в качестве экзогенного фактора модернизационного процесса. Утверждается, что технологизация имеет, помимо собственных сугубо материально-технического и экономического смыслов, еще и инструментальное значение как комплексного регулятора социальных процессов и состоит из ложных приемов структурно-функционального воздействия на политическую, социальную и духовноценностную сферы современного общества. Отмечено, что социально-политическая модернизация оказывается в тесной взаимозависимости с технологической модернизацией. При этом довольно сложное взаимодействие происходит между треками развития этнических и национальных культур и процессом политической модернизации.

Ключевые слова: технологизация, модернизация, социокультурная модернизация, консервативная модернизация, демократия, авторитаризм.

Развитие современного общества является разновекторным и неравномерным по своему характеру процессом и может быть представлено самым различным образом в свете социальных теорий современности. Среди теорий, релевантно, на наш взгляд, описывающих процессы развития современного общества, следует особо указать на массив теорий информационного общества и сопутствующие им концепции общества знаний. Если говорить о классических подходах информационного общества, развивающихся уже более полувека, то среди многочисленных теоретиков и футурологов необходимо упомянуть таких хрестоматийно известных ученых (труды которых активно публикуются в России в последнее время), как Элвин Тоффлер [Тоффлер 2008; 2010] и Джон Нейсбит [Нейсбит 2003]. Концепция общества знаний завоевала свое научное признание благодаря работам Фрица Махлупа [Machlup 1962] и Даниэла Белла [Bell 1973].

Среди современных ученых, работающих в парадигме информационного общества, стоит указать на калифорнийского профессора Мартина Хилберта, исследующего влияние цифровых технологий на социальные изменения. В частности, в ходе проведения долгосрочных и многочисленных исследований им с сотрудниками были рассмотрены: всемирный технологический потенциал хранения, передачи и вычисления информации [Hilbert, Lypez 2011], динамика цифрового неравенства в обществе [Hilbert 2014], а также социальное поведение субъектов, связанное с современными каналами коммуникации [Hilbert et al. 2019]. На наш взгляд, стоит упо- мянуть другого современного калифорнийского ученого - Микаэля Бакленда, анализирующего культурное наследие и историческое развитие теории управления информацией [Buckland 2019].

Становится очевидным, что в рамках социально-информационной парадигмы центральным является вопрос о стратегиях технологизации социальных практик и их последствий для общества в целом и для отдельных социальных субъектов. На это обстоятельство обращают внимание и отечественные исследователи, работающие над данной проблематикой.

Особую значимость рассмотрение и анализ данных проблем имеет для описания процессов, происходящих в современном российском обществе, ведь технологизация социальных практик изменяет структуру и формы процессов коммуникации между социальными субъектами и динамику развития и функционирования различных элементов социальной системы. В рамках современных социальных процессов становятся все более очевидными новые прагматические и динамические аспекты динамики знания, в результате чего знание является не только важным ресурсом развития общества, но и существенным фактором личностного роста и устойчивого существования индивида в бурно изменяющемся мире [Бакланов, Бакланова, Авдеев 2014].

Более того, современное общество можно репрезентовать как техногенное, ведь во многом его особенности порождены современными технологиями. В связи с этим имеет смысл говорить о технологизации как о факторе изменения социального и культурного про- 
странства, вернее как о факторе социокультурной модернизации. Действительно, технологизация представляет собой процесс, теснейшим образом связанный с политическими, экономическими, культурными процессами в обществе [Пелевин 2019]. Именно поэтому технологизацию нельзя исследовать как автономный, самостоятельно развивающийся процесс: ее наличие всегда предполагает тесную корреляцию с другими социокультурными изменениями.

В целом технологизация общества может быть понята как процесс поэтапного структурного и функционального перехода всех общественных систем от традиционного общества к индустриальному и затем - к постиндустриальному, а также как формирование и утверждение в обществе новых институтов и современных системных особенностей. Это своего рода материальное организационное сопровождение тех ценностных и социокультурных процессов, которые происходят в процессе технологизации общества в целом [Хантингтон 2004, 53].

В различных странах эти процессы технологическая модернизация в разных сферах общества, от экономической до духовной - проходят неодинаково и хронологически неравномерно, полихронно. Кроме того, они обладают выраженной внутренней логикой и последовательностью развития лишь в тех странах, которые можно исторически отнести к «первому эшелону» модернизации, то есть сначала в развитых капиталистических государствах Западной Европы, а уже затем в Соединенных Штатах Америки. Политические изменения в этих странах были осуществлены в ответ на происходящие техногенные изменения в обществе, его повседневной жизни и первоначально востребованы именно социокультурной сферой, а не наоборот.

Говоря о странах «второго и третьего эшелона» модернизации, можно отметить, что выраженной политической модернизации, проводимой в них, не было или практически не было заметно из-за их слабости внутренних импульсов и слабых качественных техногенных изменений в обществе. Особенностью модернизации этих стран стало то, что она проводилась в них вынужденно, несмотря, а иногда и вопреки тем политическим потреб- ностям, которые назревали в них изнутри. То есть технологизации экспортировались в общество и усваивались, а глубоких социокультурных изменений в нем это не порождало.

Это привело к появлению такого противоречивого, на первый взгляд, политического феномена как «консервативная» модернизация.

Первый тип консервативной модернизации можно было наблюдать в Японии и России XIX в., когда политические верхи затевали системное обновление во избежание более радикальных разрушений старых порядков. Фактически, систему «ремонтировали», подстраиваясь под новые мировые веяния для того, чтобы сохранить ее в традиционном русле развития. Правительство этих стран пыталось «перестраивать» свою политическую систему, борясь одновременно с наиболее реакционно настроенными слоями правящего класса [Карелова 2012, 184].

Второй тип консервативной модернизации, который можно было наблюдать во второй половине $\mathrm{XX}$ в. в странах Восточной и Юго-Восточной Азии, отличался от первого тем, что правящие круги модернизирующихся стран были ориентированы в будущее, однако понимали, что в социокультурной сфере их стран не сложилась объективная внутренняя потребность разрыва с прошлым. Для того, чтобы создать данную потребность, приходилось искать точки преемственности и оправданности грядущих перемен в многовековых, чаще всего религиозных традициях [Иванова 2011, 419].

Необходимо заметить, однако, что во всех сценариях развития консервативной модернизации существует одна и та же проблема. При дальнейшем социокультурном развитии построенной в этих странах экономической системы традиции, играющие поначалу позитивную амортизирующую роль, становятся препятствием для дальнейшего перехода к постиндустриальной системе, предполагающей переход от «вертикальных» к «горизонтальным» типам социальных связей, все возрастающую подвижность и гибкость системы, возрастание степени свободы и разлом иерархических лестниц [Мурзанова 2016].

Политический режим оказывает очень большое влияние на процессы модернизации социокультурной и экономической сферы об- 
щества (как развивающиеся изнутри, так и приходящие извне), он может как выступать в отношении них в качестве ускоряющего фактора, катализатора, так и становиться замедляющим фактором в том случае, если это развитие не когерентно ценностям, лежащим в основании социальных практик.

При этом существует и обратное влияние. Даже если технологическая и техническая модернизация катализирует экономическую модернизацию, далеко не всегда это влечет за собой развитие политической сферы. В случае «вторичной» модернизации чаще всего получается, что модернизированными оказываются только некоторые фрагменты политической системы, поскольку политическая модернизация - это тоже длительный очень специфический процесс, во многом зависящий от того, какой режим и как долго существовал в стране, насколько он связан с представлениями населения о власти и до какой степени был легитимным, как он соответствует ценностному запросу общества, который не всегда на практике оказывается непротиворечивым [Никитин 2010, 75].

Если авторитарный режим в государстве меняется на демократический, то это еще не гарантирует стабильности последнего, скорее напротив: демократический режим, установившийся в обществе, имеющем в своем сознании запрос на авторитаризм, подвергает социальный порядок серьезному риску.

Многое в данной ситуации зависит от того, каковы были мотивы этой модернизации. Если имела место негативная мотивация (например, общество консолидировалось только на одном нежелании иметь репрессивную власть, или власть, неудачно ведущую экономическую политику), на дальнейшую солидарность различных слоев общества рассчитывать сложно. Возникший демократический режим будут сотрясать перманентные встряски, вызванные стычками различных, не согласных между собой социальных групп. Такая демократия не способна решать накопившиеся экономические и социальные проблемы, поскольку у нее нет для этого ресурса власти, а политическую сферу раздирают между собой различные политические и экономические силы. При этом общественное сознание воспринимает такие периоды, как «упадок» вла- сти, ее слабость, оно склонно недооценивать возможности демократии и устойчиво востребует «сильную руку» [Мурзанова 2016, 53].

Другое дело, если демократия устанавливается в государстве в процессе естественной структурной миграции от «вертикальной» к «горизонтальным» формам управления и построения гражданского общества. В этом случае многое зависит от гибкости самой системы и дальновидности тех, кто оказался у рычагов ее управления. Старые политические и правовые институты, доставшиеся в наследство от авторитарного режима, нуждаются либо в сознательном и последовательном демонтировании, либо (это в лучшем случае) эволюционно обретают новые политические и экономические функции, что обеспечивает преемственность и перерождение политических традиций, никогда не меняющихся скачкообразно. Падение авторитарного режима или его постепенная эрозия - это еще не залог успешного развития нового демократического режима. Это всего лишь создание необходимого условия для начала нового процесса построения устойчивого демократического режима, не обещающего стабильности.

На протекание социокультурной модернизации большое влияние оказывает мировой техногенный контекст, выступающий в качестве экзогенного фактора модернизационного процесса. Это влияние многоаспектно. С одной стороны, это прямое технологическое внедрение через экономическую систему, с другой - прямое или косвенное формирование политического запроса в модернизирующихся странах на демократический режим.

Политически и экономически развитый Запад (чаще в лице США) зачастую довольно бесцеремонно вторгается во внутренние дела менее развитых в технологическом и экономическом смысле стран. Вторжение может быть технологическим или экономическим, когда развитые страны выносят ряд промышленных отраслей в менее развитые регионы (как происходило, например, со странами Латинской Америки и Азии). Вкупе с политическими условиями сложились определенные социально-экономические предпосылки для установления и поддержания модернизационных авторитарных режимов, обеспечивавших начиная с 60-х гг. XX в. развитие 
ряда латиноамериканских стран. Большое значение имеет место «отнесения» государства к странам «первого», «второго» или «третьего» мира по уровню политического «веса» на международной арене и свободы действия внутри собственной страны и за ее пределами.

В существенной мере стремительно начавшиеся и набирающие обороты процессы глобализации оказывают влияние на внутренние социокультурные и политические модернизации отдельных стран. Например, с 80-х гг. $\mathrm{XX}$ в. в странах «третьего» мира начинается постепенное отступление авторитаризма, которое совпадает с модернизацией в Китае и Вьетнаме, на него специфическим образом влияет разрушение Советского Союза и формирование «однополярного мира». Нельзя говорить, что именно постиндустриальные тренды играют в данном процессе решающее значение, однако нужно помнить, что они, со своей стороны, создают благоприятный мировой контекст, но сами по себе не предполагают перехода от авторитаризма к демократии [Работяжев 2009].

Иногда можно наблюдать обратные тенденции: под влиянием тех же мировых постиндустриальных трендов разрушается промышленный рабочий класс, ухудшается положение среднего класса, происходит эрозия в системе образования, начинаются неконтролируемые процессы в самой культуре, что может сформировать у населения (любой его части) запрос на авторитаризм, как происходит с разной степенью интенсивности последние 20 лет в России и странах так называемого «социалистического лагеря» [Фисун 2006, 168].

Таким образом, социально-политическая модернизация оказывается в тесной взаимозависимости с технологической модернизацией, хотя они, строго говоря, по своему характеру представляют собой различные, хоть и взаимообусловленные процессы. В частности, довольно сложное взаимодействие происходит между треками развития этнических и национальных культур и процессом политической модернизации. Непростым также бывает соотнесение нового устанавливающегося политического режима с культурными традициями, ценностями, веками сформированной идентичностью. Тем не менее роль процесса технологизации общества как фактора социокультурной модернизации постоянно возрастает практически во всех уголках земного шара.

\section{СПИСОК ЛИТЕРАТУРЫ}

Бакланов, Бакланова, Авдеев 2014 - Бакланов И.С., Бакланова О.А., Авдеев Е.А. Знание в современных социальных процессах: прагматический и экзистенциальный аспект // Соврем. пробл. науки и образования. 2014. № 3. С. 673.

Иванова 2011 - Иванова Е.А. Политическая модернизация арабского востока: между государством и консервативной революцией // Науч. ежегодник Ин-та философии и права Урал. отд-ния РАН. 2011. № 11. С. 419-433.

Карелова 2012 - Карелова Л.Б. Проблемы модернизации Японии и межкультурное взаимодействие // Вестник МГИМО. 2012. № 6 (27). C. $183-186$.

Мурзанова 2016 - Мурзанова Л.А. Соотношение охранения и модернизации в консервативной мысли // Философия и общество. 2016. № 4 (81). C. 53-62.

Нейсбит 2003 - Нейсбит Дж. Мегатренды. М.: АСТ: Ермак, 2003.

Никитин 2010 - Никитин А.П. Понимание собственности в консервативном и либеральном мировоззрении: к проблеме выделения индикаторов социокультурной модернизации // Вестник Новосиб. гос. ун-та. Сер.: Философия. 2010. Т. 8, №4. С. 73-77.

Пелевин 2019- Пелевин С.И. Современное общество в контексте технологических процессов: социально-философский анализ // Kant. 2019. № 1 (30). C. 213-217.

Работяжев 2009-Работяжев Н.В. Консервативная геополитическая мысль в России: преемственность и обновление // Вестник Моск. унта. Сер. 12, Политические науки. 2009. № 5. C. 74-94.

Тоффлер 2008 - Тоффлер Э. Шок будущего. М.: ACT, 2008.

Тоффлер 2010 - Тоффлер Э. Третья волна. М.: АСТ, 2010.

Фисун 2006 - Фисун А. Демократия, неопатримониализм и глобальные трансформации. Харьков: Константа, 2006.

Хантингтон $2004-$ Хантингтон С. Политический порядок в меняющихся обществах. М.: Прогресс-Традиция, 2004.

Bell 1973 - Bell D. The Coming of Post-Industrial Society: A Venture of Social Forecasting. N. Y.: Basic Books, 1973. 
Buckland 2019 - Buckland M. Information and Society. Cambridge, MA: MIT Press, 2017.

Hilbert 2014 - Hilbert M. The Bad News is That the Digital Access Divide is Here to Stay: Domestically Installed Bandwidths Among 172 Countries for 1986-2014// Telecommunications Policy. 2016. № 40 (6). P. 567-581.

Hilbert et al. 2019 - Hilbert M., Liu B., Luu J., Fishbein J. Behavioral Experiments with Social Algorithms: an Information Theoretic Approach to Input-Output Conversions // Communication Methods and Measures. 2019. № 1 (1). P. 1-20. DOI: https://doi.org/10.1080/19312458.2019. 1620712.

Hilbert, Lypez 2011 - Hilbert M., Lypez P. The World's Technological Capacity to Store, Communicate, and Compute Information // Science. 2011. № 332 (6025). P. 60-65.

Machlup 1962 - Machlup F. The Production and Distribution of Knowledge in the United States. New Jersey: Princeton University Press, 1962.

\section{REFERENCES}

Baklanov I.S., Baklanova O.A., Avdeev E.A., 2014. Knowledge in Modern Social Processes: a Pragmatic and Existential Aspect. Sovremennye problemy nauki i obrazovaniya, no. 3, pp. 673.

Ivanova E.A., 2011. Political Modernization of the Arab East: Between the State and the Conservative Revolution. Nauchnyj ezhegodnik Instituta filosofii i prava Ural'skogo otdeleniya Rossijskoj akademii nauk, no. 11, pp. 419-433.

Karelova L.B., 2012. Problems of Modernization of Japan and Intercultural Interaction. Vestnik MGIMO, no. 6 (27), pp. 183-186.

Murzanova L.A., 2016. Ratio of Protection and Modernization in Conservative Thought. Filosofiya i obshchestvo, no. 4 (81), pp. 53-62. Naisbitt J., 2003. Megatrends. Moscow, AST, Ermak.
Nikitin A.P., 2010. Understanding Property in a Conservative and Liberal World View: to the Problem of Highlighting Indicators of Sociocultural Modernization. Vestnik Novosibirskogo gosudarstvennogo universiteta. Seriya: Filosofiya, vol. 8, no. 4, pp. 73-77.

Pelevin S.I., 2019. Modern Society in the Context of Technological Processes: Socio-Philosophical Analysis. Kant, no. 1 (30), pp. 213-217.

Rabotyazhev N.V., 2009. Conservative Geopolitical Thought in Russia: Continuity and Renewal. Vestnik Moskovskogo universiteta. Seriya 12: Politicheskie nauki, no. 5, pp. 74-94.

Toffler A., 2008. Shock of the Future. Moscow, AST. Toffler A., 2010. The Third Wave. Moscow, AST.

Fisun A., 2006. Democracy, Non-Atomism and Global Transformation. Harkov, Konstanta.

Huntington C., 2004. Political Order in Changing Societies. Moscow, Progress-Tradicija.

Bell D., 1973. The Coming of Post-Industrial Society: A Venture of Social Forecasting. New York, Basic Books.

Buckland M., 2017. Information and Society. Cambridge, MA, MIT Press.

Hilbert M., 2014. The Bad News is That the Digital Access Divide is Here to Stay: Domestically Installed Bandwidths Among 172 Countries for 1986-2014. Telecommunications Policy, no. 40 (6), pp. 567-581.

Hilbert M., Liu B., Luu J., Fishbein J., 2019. Behavioral Experiments with Social Algorithms: an Information Theoretic Approach to InputOutput Conversions. Communication Methods and Measures, no. 1 (1), pp. 1-20. DOI: https:// doi.org/10.1080/19312458.2019.1620712.

Hilbert M., Lypez P., 2011. The World's Technological Capacity to Store, Communicate, and Compute Information. Science, no. 332 (6025), pp. 60-65.

Machlup F., 1962. The Production and Distribution of Knowledge in the United States. New Jersey, Princeton University Press.

\section{Information About the Author}

Sergei I. Pelevin, Associate Professor, Department of Philosophy, Law and Social Sciences, Armavir State Pedagogical University, Rosa Luxemburg St., 159, 352901 Armavir, Russian Federation, pelevin17@gmail.com, https://orcid.org/0000-0002-3415-752X

\section{Информация об авторе}

Сергей Игоревич Пелевин, доцент кафедры философии, права и социально-гуманитарных наук, Армавирский государственный педагогический университет, ул. Розы Люксембург, 159, 352901 г. Армавир, Российская Федерация, pelevin17@gmail.com, https://orcid.org/0000-0002-3415-752X 